\title{
Urgences
}

Hélène Gauthier-Chassé, À diable-vent. Légendaire du Bas-Saint-Laurent et de la Vallée de la Matapédia, Montréal, Les Quinze éditeur, coll. " Mémoires d'homme ", 142 p.

\section{Lise Lessard}

Numéro 3, 4e trimestre 1981

URI : https://id.erudit.org/iderudit/025051ar

DOI : https://doi.org/10.7202/025051ar

Aller au sommaire du numéro

Éditeur(s)

Urgences

ISSN

0226-9554 (imprimé)

1927-3924 (numérique)

Découvrir la revue

Citer ce compte rendu

Lessard, L. (1981). Compte rendu de [Hélène Gauthier-Chassé, À diable-vent. Légendaire du Bas-Saint-Laurent et de la Vallée de la Matapédia, Montréal, Les Quinze éditeur, coll. " Mémoires d'homme ", 142 p.] Urgences, (3), 92-93.

https://doi.org/10.7202/025051ar d'utilisation que vous pouvez consulter en ligne.

https://apropos.erudit.org/fr/usagers/politique-dutilisation/ 
En terminant, je me permets de revenir à l'avant-propos (décidément!) pour retrouver ces phrases: "Écrire un livre... tient autant de la témérité que de la folie..." (9) "Mettre un livre au monde, c'est permettre à la liberté d'expression, si fondamentale, d'avoir cours". (10) Ne fut-ce que pour cela, le livre mérite d'être
(1) page 17
(2) page 9
(4) page 16
(7) page 49
(3) page 14
(5) page 17
(8) page 39
(6) page 21
(9) page 10
(10) page 10

\begin{abstract}
"A DIABLE-VENT" d'Hélène Gauthier-Chassé, Éditions QUINZE, collection Mémoires d'homme.
\end{abstract}

Comme il n'y a même pas besoin d'y croire pour les savourer, et qu'au contraire le fait même d'en douter ajoute toujours au plaisir de les lire (le rire étant une occupation si agréable!) les LÉGENDES ET CONTES POPULAIRES, que taisent de plus en plus les voix tremblotantes et joyeuses de nos grand-pères (car qui encore aujourd'hui a la chance d'en avoir un dans sa boîte à lunch ou son sac d'école?) ne sauront disparaître comme par enchantement, tant que des auteurs, amoureux de ces "vieilleries" qui font partie intégrante de Notre Histoire, partiront avec curiosité et sensibilité les cueillir comme $\mathrm{d}^{\prime \prime}$ "immortelles" immortelles.

Et qui plus est, tant que ces mêmes amoureux s'intéresseront aux transformations que le temps et les gens ne peuvent manquer invariablement de leur faire subir, comme étant la preuve indéniable de leur pérennité. Car, "rien ne meurt de façon simple" comme le dit elle-même Hélène Gauthier-Chassé, dans la Préface de son "légendaire" A DIABLE-VENT paru dans Mémoires d'homme, aux éditions QUINZE. Elle nous y offre, avec une joie évidente et une grande finesse, un répertoire de certaines légendes du Bas Saint-Laurent et de la Vallée de la Matapédia. S'y côtoient, comme de bien entendu, les diables, les feux follets, les poules noires, les maisons hantées, les roches enchantées, les bals du Mardi-Gras qui se terminent par des planchers brûlés et des empreintes de griffes sur des épaules blanches. (Nos bonnes vieilles légendes!!!). 
Mais son approche, très nouvelle dans le genre, va plus loin que la transcription traditionnelle, car elle a aimé le conteur autant que le "conté". Son respect pour lui exclut l'intervention et, ce qui est extrêmement intéressant, mentionne les divergences de ses sources d'information. Elle ajoute ensuite - délicieux - ses commentaires pleins d'humour - qui ne se moque jamais mais taquine chez toi, lecteur, ta propre incroyance (si j'ose dire!)!

Le tout agrémenté de nombreuses citations d'écrivains et d'historiens des siècles passés ayant traité les mêmes sujets, de paroles de très anciennes chansons se rapportant aux contes populaires ainsi que leur musique, d'illustrations, d'un glossaire, et d'une bibliographie consistante pour les autres "amoureux" d'histoires vécues (!).

Consciente de l'arbitraire de ces croyances populaires selon que l'on se trouve dans une région ou dans l'autre: l'instant géographique, religieux ou sociologique n'apportant jamais la même interprétation à un événement insolite, elle habille ce "genre littéraire" d'une truculence qui lui "fait" très bien. Témoin cet aveu amusant d'un sceptique: (.87) - “Moi, j'crois pas au diable, à rien de ces affaires-là... J'crois pas que les Américains ont été sur la lune non plus, même si je l'ai vu à la télévision... Avec leurs bebelles perfectionnées ils peuvent faire accroire n'importe quoi! C'est crasse du monde, vous savez!... A moins des vieux prêtres malades qui aimaient effrayer les gens, j'en ai jamais connu d'assez imbéciles pour nous faire des peurs avec des affaires de diable. C'est pourquoi j'en raconte pas, que j'en ai jamais raconté à mes enfants non plus. Je vous regarde là, vous avez l'air maligne en plein, comment pouvez-vous penser faire un livre avec ça, pour l'amour du bon Dieu?".

Ouvrez-le donc pour voir!

Lise Lessard 